\title{
A New Research Tendency for Online Marketing Using User-Generated Content of Online Platforms
}

\author{
Wei Deng ${ }^{1, a}$, Shang-Te Tsai ${ }^{2, b} *$, Cheng-Fu Yang ${ }^{3, c_{*}}$ \\ ${ }^{1}$ Department of Economics and Management, Ningde Normal University, China \\ ${ }^{2}$ Department of Economics and Management, Ningde Normal University, China \\ ${ }^{3}$ Department of Chemical and Material Engineering, National University of Kaohsiung, Kaohsiung, Taiwan, R.O.C. \\ a492571091@qq.com, bfeilongzz@gmail.com, ${ }^{c}$ cfyang@nuk.edu.tw \\ *Corresponding author: feilongzz@gmail.com
}

\begin{abstract}
In the past, the information of traditional travels is supplied by the travelling agencies. However, as the data on the user-generated content (UGC) system is used, the information feedback by the travelers has truly responded their requirements. A destination marketing organization (DMO) is an organization that promotes a town, city, region, or country in order to increase the number of visitors. In order to provide better and precision images for the travelers, DMO will supply new idea and method for selling the travel package. Today, the internet marketing has become the most important selling method. Thus, the internet marketing contents constructed by DMO are usually based on the subjective judgement, but they do not give sufficient consideration to the image feeling. UGC system can supply plentiful analysis materials, and it can also combine the new technologies of big data and machine learning system. For that, it can construct a quantifiable and reproducible selling structure of purpose. It promotes the development and marketing of a destination, focusing on convention tourism marketing and services.
\end{abstract}

Keywords: User-generated content; Travelers; Destination marketing organization; Big data; Machine learning system

\section{Introduction}

User-generated content (UGC), can also be called as user-created content (UCC), is the different contents created by users of a system or service, and those data is available and publicly on the system. UGC consists of any form of content that's created by users and consumers about a brand or product. UGC is public information that a person can contribute and provide to a web site without any pay. The information of UCG might be a photo, video, blog, or discussion forum post, poll answers or comments made through a public and social media web site. UGC isn't paid for, and it really makes the user the brand advertiser as well. UGC system is become more important in the research of traveling quantify because of its advantages of high reality, high objectivity, and immenseness data. Because of the great development the information search and the decision-making process of tourists have received great attention in tourism research literature and both are considered to be important theoretical and practical topics. Pesonen and Pasanen found that banners and social media do not seem to play an important role in new customer acquisition in the online marketing, but search engine optimization and content in the internet marketing as well as product quality are at the top of the lists. The two main core objects of the online marketing are the choice of selling products and the construction of selling channels [1]. And the choosing contents of the products can be regarded as what kind of source materials the destination marketing system will be used, including the pictures for vision type and the descriptions of manuscripts.

Over the Air Technology (OTA) is one kind of wireless download technologies, which can remotely control and manage the data in SIM card in the air by the mobile telecommunication systems of GSM or CDMA. In the aspect of distributing channels the searching engine is $40 \%$ more than the tour websites of OTA and others, which's searching rate is the main entrance of internet tour guide. In the aspect of content choice manuscripts and figures are the two main formats. So far, some researches of manuscripts have touched the field of selling, but only few researches are focused on the field of tour selling. About the choice of photo content, so far some articles had discussed the relationship between the photo content and motive of potential tourists, which analyzed how the photos can excite the tourists having feeling with purposes. Pan et al said that travel photos can be symbols reflecting inner feelings of the photographers. They also serve as records that store travel experience of the photographers [2]. They also found that the image dimensions of natural resources such as "wealth of countryside", "flora and fauna", and "beaches" are frequently associated with "arousing" and "pleasant" feelings toward a purpose.

It means that as the DMO backing on photos can help the image injection and sell of the destinations, which is the reason that the photos can excite the tourists having the motive for tour. Chen's research had discussed that different photo sender and receiver will generate different feeling on the same photo [3]. This is the important reason that the tour purpose will cause the difference in the images of injection and felling. Search engine optimization (SEO) is the process, which can affect the online visibility of a web page or a website in an online or web search engine's unpaid results. The SEO system is often referred to as "natural", "organic", or "earned" results. Chen et al had tried to predicting what viewer affect concepts will be triggered when the image is perceived by the viewers. They also said that if the media content publishers give an image tagged with "yummy food", the viewers are likely to comment "delicious" and "hungry", which we refer to as viewer affect concepts (VAC) [4].

In general, the earlier (means having higher ranking on the search results page) and more frequently a website appears in 
the search results list, the more visitors it will receive from the search engine's users. These visitors can then be converted into potential customers for the online selling products. In the choice of searching channels, many discussions about using the searching engine for selling products had been investigated, and these discussions focused on the keywords of optimization and buy. For example, Huang et al used co-integration theory and Granger causality analysis to find the relationship between the internet search data and the actual tourist flow [5]. Their study shows that a long-term equilibrium relationship and Granger causal relation exist between the observed and statistical number of tourists and a set of related keywords in the Baidu Index. They compared the statistical data with the Baidu Index daily keyword search volumes for the corresponding period, they find that there is a consistent relationship between the changes of 'The Palace Museum ticket' daily search volume and the trend of actual number of tourists.

Also, Li et al had adopted online data such as searching engine query volumes to forecast tourism demand for a purpose, including tourist numbers and hotel occupancy [6] Their study addressed the importance of search index aggregation and they encouraged more studies to use Google or Baidu search data for tourism forecasting. According to the data, they suggest that in the slack and boom seasons merchants can use different marketing strategies and tourists' management. According to these statements, researches for the field of online marketing for construction and optimization of selling channels are just starting. How to construct and optimize the selling channels from the popular views are the key points for efficiency selling. UCG data can supply high value of source data for the aim of tour package selling, then people can choose the reasonable products and channels to improving their tour's movements.

\section{Research examples of online marketing for tours based on UCG big data}

\section{Optimizing frame of pictures based on the selling goal} based on social UCG

The Chinese Government's action plan on the Internet+ ecosystem, which integrates mobile Internet, cloud computing and big data together with the online-to-offline (O2O) strategic alliance of virtual and physical stores, reveals its aspiration toward the development of a consumer orientation in e-commerce activities [7]. Publisher cognitive conception (PCC) of learning can guide future research on both learnings and instructions. As a proof-of-concept, Ali et al proposed a linear admixture model for modeling these relations, and the resulting computational framework allows us to determine the associations between each emotion class and certain High-Level Concepts (HLCs, objects and places), which is the idea of viewer affective concept (VAC). Ali et al used HLCs generated by pretrained convolutional neural networks (CNNs) in an explicit way to investigate the relations/associations between these HLCs and a small set of Ekman's emotional classes. Their experiments have demonstrated that their results are comparable with a clear view of the association between HLCs and emotional classes, which are ostensibly missing in most research works [8].
A picture is worth a thousand words", how DMO to choose the purpose of selling photos is the most important problem. We can use the mass UCG photos and comments of tourists to construct the model for the set of content and feeling with PCC and $\mathrm{VAC}$, and further to construct the relationship model between PCC and VAC. As the photos are chosen by the machine of UGC system, which has learned the algorithm, the photos can be ordered in priority according to the potential people's probability. One kind of real application is that DMO system chooses a few photos, which has matched one special topic, for example happy. DMO system also uses the algorithm to sequence the order, the photos in the top ranks are considered to excite the people's "happy" feeling. Figure 1 shows the results of UCG system pick photos with some special topics to sequence their order. The photos in the top ranks can excite the more people's "happy" feeling.

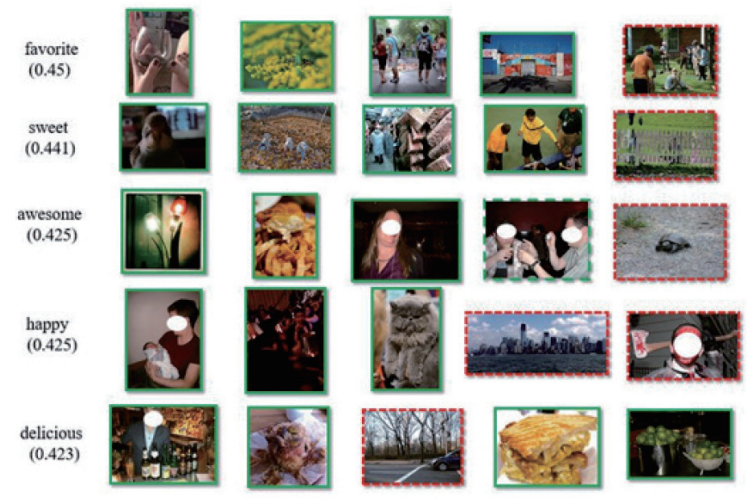

Figure 1. Photo ranking using machine learning algorithm

2. Construction of social-based fans portrait on network for the purpose of selling

Table 1 is the mapping between interest tags and affective motives using Censydiam mode. It is easy to observe and measure the overt rationales consumers use to justify purchases. As with an iceberg, however, the most powerful drivers of consumer satisfaction strategies lie beneath the surface. Censydiam's model yields a powerful tool to harness the insights of depth psychology for effective marketing [9]. The field of product design has some researches using the Censydiam model to analyze the intrinsic motivation of consumers. These researches also can mix the motivation with the product design in order to induce the user to buying some products, and there are some similar method being investigated in the selling field. Using the data of fans portrait on Weibo website mix with the Censydiam model can transform the users' habit into inducing purchasing behavior. Data in UGC system can be used as a consultant for constructing the content of tour selling. Using the social-based fans portrait on network we can derivate and analyze the tour motivation for the destination fans.

Using the data in Table as example, according the analyses for the photos of the Imperial Palaceon on Weibo website the favorites or occupations of fans in the top five are "medium", "literature", "zany", "video", and "motion comic". According to the Censydiam analysis model of consuming motive and 
matching with the feeling motive the reason for the Imperial Palaceon attracting the tourists is "Enjoy, relaxing", "Personality, individuality", and "Animation, exploration". For that, if above elements or contents are added in the marketing documents of the Imperial Palaceon, the more feeling vibration will happen in the consumers.

\section{Purpose of feeling image based on the UCG system optimization research of search engine}

Passing through search engine and guiding consumers to the website is an important method for marketing. Ordering the relative sentences or words is usually using method for the optimization of search engine. How to choose the representative words for the destination and to mix effectively with the images of destination the UCG system can match the public expectation, which is important for online marketing [10]. Hunter's research had found that as using visual semiotics, the social construction of tourism online destination image can be investigated in terms of denotative and connotative signs. His major findings suggest that the organic online self-representation of individual travel experiences by travelers, makes tourism as a soft power more effective, by supplementing the projected image of Seoul. Purpose image is formed by three distinctly different but hierarchically interrelated components called cognitive, affective, and conative [11].

Using Beijing as example, when we use the photos and manuscripts choosing in Flickr for analysis, we can get the cognitive images of destination and the analyzing results are shown in Table 2 for the high frequency keywords of Beijing destination image from Flickr photo's metadata. We can use these as the optimizing keywords of search engine to buy the sentences and words, these can save the marketing cost and guide the searching flow from website entrance to our destination. In actual application process we not only need to consider keywords of destination but need to totally considerate the price of the keywords in the search engine. As the marketing cost is controlled, searching flow can be guided in the optimum efficiency, that will be the real example for using the big data of UCG system for the online marketing.

In this study, we used the metadata from Flicker and with the Yahoo Flickr Creative Commons 100 Million (YFCC100m) dataset to design and achieve using the pictures in a social platform to carry out the data picking and analyzing platform- Photo based Metadata Mining System (PMMS). The PMMS can have four service functions about the research of tour pictures: (1) analysis of Point of Interest (POI), (2) comparison and analyses of tourists' past records, (3) analysis of tourists' travel path, and (4) analysis of destination image sensory based on the pictures.

\section{Discussions and Conclusions}

From the researches we know that UGC can generate more engagement on Instagram -- meaning more comments and likes on posts. And engagement is critically important to tourism marketing and service success on the platform -because the more tourists engage with your platform, the higher your posts are prioritized in the Instagram feed, and the more likely it is that new tourists will find your content on the internet platform. The three examples introduced above are researches belong to investigating using the data in UCG system for marketing optimization. These examples prove that the DMO system can provide the technology and theorem for destination selling from three different methods of channel optimization, content construction, and photo optimization. UGC system has the advantage of the power of the collective, and smart marketers of tour DMO will react to trends by creating opportunities for travelers to tell their own version of the story. Using UCG big data has the chance to achieve quantifiable and being duplicated new marketing method, the main advantage and limit for that are listed below:

\section{Main advantage}

Using UGC big data can have the advantages for the optimization of destination online marketing: (1) It is easy to obtain data, because the social websites have provided big data, which can help to examine tour selling from the feeling of tourists. (2) No matter the UCG photos are obtained from the photo optimization or from fans photo of social websites, they are chosen and constructed from the people's viewpoint. For that, they can excite the vibration of people's feeling and optimize the selling efficiency. (3) Method can be quantifiable and being duplicated, using the above method for contents of destination selling and construction is not limited and has universality.

\section{Main limit}

UGC is not a new concept, but it is snowballing to become the most powerful and important tool digital marketers have at their disposal. Because of the quick development of internet UGC becomes the modern version of talking over the garden fence - nothing tools and sellers can create themselves being compared to the basic human love of gossip and themselves. For that, analyzing the big data for tourism marketing and services has become more and more important. However, using big data for the contents of destination selling and construction also has two limits: (1) some destinations are not famous to people and there may be insufficient UCG data, those will affect the efficiency. (2) Using UCG data for subject selling or content construction is an assisting method for DMO selling, the efficiency and correction of this algorithm have to being improved.

\section{References}

[1] J. Pesonen and K. Pasanen, "A Closer Look at Tourist Information Search Behaviour When Travelling Abroad: What Is the Role of Online Marketing in Choice of Destination?,'. Inform. Commun. Techn. in Tourism 2017. Berlin, Springer, pp. 431 443, 2017.

[2] S. Pan, J. Lee, H. Tsai, "Travel photos: Motivations, image dimensions, and affective qualities of places," J. Tourism Management, Vol.40, pp. 59 69, 2014.

[3] Y.Y. Chen, T. Chen, W.H. Hsu, et al. "Predicting Viewer Affective Comments Based on Image Content in Social Media," The Proceedings of International Conference on Multimedia Retrieval, 2014.

[4] A. Ortiz-Cordova and B.J. Jansen, "Classifying Web Search Queries in Order to Identify High Revenue Generating Customers," J. Amer. Soc. Information Sci. Tech. Vol. 63, no.7, pp. $1426-1441,2012$. 
[5] X. Huang, L. Zhang, Y. Ding, "The baidu index: Uses in predicting tourism flows - A case study of the Forbidden City," Tour. Manage. Vol. 58, pp. 301 306, 2017.

[6] X. Li, B. Pan, R. Law, et al. "Forecasting tourism demand with composite search index," Tour. Manage. Vol. 59, pp. 57 66, 2018.

[7] M. Cheung and C.F. Yang, "The E-Commerce Revolution: Ensuring Trust and Consumer Rights in China," IEEE-ICICE 2017, November 6 - 11, 2017, Kunming, P.R. China.

[8] A.R. Ali, U. Shahid, M. Ali, J. Ho, "High-Level Concepts for Affective Understanding of Images," 2017 IEEE Winter Conference on Applications of Computer Vision (WACV), 24-31 March 2017, Santa Rosa, CA, USA.

[9] J. Callebaut, H. Hendrickx, M. Janssens, The Naked, "Consumer
Today: Or an Overview of Why Consumers Really Buy Things, and What this Means for Marketing," Belgium: Garant, 2002.

[10] W.C. Hunter, "The social construction of tourism online destination image: A comparative semiotic analysis of the visual representation of Seoul," Tour. Manage. Vol. 54, pp. 221 229, 2016.

[11] U. Basaran, "Examining the Relationships of Cognitive, Affective, and Conative Destination Image: A Research on Safranbolu, Turkey,", Inter. Business Resear. Vol. 9, No. 5, pp. 164 179, 2016

[12] B. Thomee, D.A. Shamma, G. Friedland, et al., "The new data in multimedia research," Communications of the ACM, Vol. 59, No.2, pp. 64 73, 2016.

Table 1. Mapping between interest tags and affective motives using Censydiam mode

\begin{tabular}{|c|c|c|c|c|c|c|c|c|}
\hline \begin{tabular}{|l} 
Feeling, motive \\
Interest, label \\
\end{tabular} & $\begin{array}{l}\text { Enjoy, } \\
\text { relaxing }\end{array}$ & $\begin{array}{l}\text { Integration, } \\
\text { communication }\end{array}$ & $\begin{array}{l}\text { Obeying, } \\
\text { belonging }\end{array}$ & $\begin{array}{l}\text { Comfortable, } \\
\text { safe }\end{array}$ & $\begin{array}{l}\text { Reasonable, } \\
\text { control }\end{array}$ & $\begin{array}{l}\text { Personality, } \\
\text { individuality }\end{array}$ & $\begin{array}{l}\text { Capability, } \\
\text { position }\end{array}$ & $\begin{array}{l}\text { Animation, } \\
\text { exploration }\end{array}$ \\
\hline Medium & & $\mathrm{V}$ & & & & $\mathrm{V}$ & & V \\
\hline Literature & $\mathrm{V}$ & & V & & & $\mathrm{V}$ & & \\
\hline Zany & V & & & & & V & & V \\
\hline Video & V & & & & & V & & \\
\hline Motion comic & $\mathrm{V}$ & & & & & $\mathrm{V}$ & & V \\
\hline Music & V & & V & V & & V & & V \\
\hline Delicacies & V & & V & V & & & & \\
\hline Design & $\mathrm{V}$ & & & & & $\mathrm{V}$ & & V \\
\hline Fashion & V & & & & & $\mathrm{V}$ & & $\mathrm{V}$ \\
\hline Tour & V & & & & & $\mathrm{V}$ & & $\mathrm{V}$ \\
\hline Score & 9 & 1 & 3 & 2 & 0 & 9 & 0 & 7 \\
\hline
\end{tabular}

Table 2. High frequency keywords of Beijing destination image from Flickr photo's metadata

\begin{tabular}{|c|c|c|c|c|c|}
\hline Keywords & Search frequency & Keywords & Search frequency & Keywords & Search frequency \\
\hline Beijing & 6175 & Architecture & 173 & Gou-Bei-Kao & 354 \\
\hline Forbidden City & 1339 & History & 279 & Allay & 254 \\
\hline Great Wall & 845 & Empire & 167 & panda & 253 \\
\hline Mu-Tien-Yu & 555 & Capital museum & 174 & Beijing zoo & 126 \\
\hline Tian An Men & 524 & Yonghe Temple & 125 & Badaling & 118 \\
\hline Chaoyang district & 440 & Temple of & 138 & Sanlitun & 77 \\
\hline Summer Palace & 378 & Heaven & 118 & Beijing roast duck & 258 \\
\hline Palace & 358 & Olympic park & 321 & Si-Ma-Tai & 102 \\
\hline Capital airport & 176 & Chaoyang park & 165 & 798 art region & 211 \\
\hline
\end{tabular}

